\title{
Bisphosphonates prevents the bone mineral loss in lymphoma patients treated with glucocorticoids: a prospective, randomized controlled phase 3 trial in China
}

Chunli Yang

West China Hospital of Sichuan University

Chunxi Fu

West China Hospital of Sichuan University

Huawei Weng

West China Hospital of Sichuan University

Liqun Zou ( $\nabla$ hxlcyxy@163.com )

West China Hospital of Sichuan University

\section{Research Article}

Keywords: Lymphoma, glucocorticoids, bisphosphonates, treatment, bone mineral loss

Posted Date: October 12th, 2021

DOl: https://doi.org/10.21203/rs.3.rs-907532/v1

License: (c) (i) This work is licensed under a Creative Commons Attribution 4.0 International License.

Read Full License 


\section{Abstract \\ Background}

Glucocorticoids-containing regimens are the standard first line treatment for most lymphoma patients, however, as the improvement of overall survival in these cases, glucocorticoids related osteopenia or osteoporosis attracted attention in clinical administration. We aim to investigate the efficacy of bisphosphonates in prevention bone mineral loss in glucocorticoids-treated lymphoma patients.

\section{Methods}

This is a prospective, randomized controlled phase 3 trial. Eligible lymphoma adults from China with first line glucocorticoids involved treatment, were randomly assigned 1:1 to receive either Zoledronic acid (ZA) for twice infusion or not. All patients received daily oral calcium and vitamin D3 for one year. The primary endpoint, alternations of bone mineral loss from enrollment to the twelfth month at the lumbar spine (L1L4), left hip and left femoral neck, measured by the dual-energy, x-ray absorptiometry scanners, recorded as T score; and new bone fractures during the first year, were analyzed by intent-to-treat. This trial was registered with www.Chictr.org, number ChiCTR-INR-17010771.

\section{Results}

Between May, 2016 to July, 2019, 84 patients were randomly assigned to both Zoledronic acid and control groups, 29 patients completed the study and were on follow-up. We found a marked improvement of T score in ZA group compared with the control in a year at lumbar spine, T score changes of L1-4 in ZA group and control group were as following: L1, $0.14 \pm 0.61$ vs. $-0.33 \pm 0.40, p=0.009 ; \mathrm{L} 2,0.28 \pm 0.41 \mathrm{vs}$. $-0.35 \pm 0.54, p=0.003 ;$ L3, $0.23 \pm 0.42$ vs. $-0.23 \pm 0.66, p=0.020 ;$ L $4,0.28 \pm 0.44$ vs. $-0.35 \pm 0.54, p=0.020$. Meanwhile, no severe adverse event was observed on both groups.

\section{Conclusions}

Glucocorticoids-treatment lymphoma patients that prophylactic ZA infusion could relieve BMD loss to prevent osteoporosis without increasing severe adverse effects in Chinese population, providing reference for clinicians to consider ZA application in this situation.

\section{Introduction}

Lymphoma is a malignant tumor derives from the immune system, including Hodgkin lymphoma (HL) and non-Hodgkin lymphoma (NHL), accounting for about $10 \%$ and $90 \%$ of all lymphoma patients, respectively ${ }^{[1]}$. In 2021, it estimates that there would be 12170 new NHL cases for men and 8550 for 
women in the United States with an increasing trend ${ }^{[2]}$. Although as a malignant tumor, prognosis of lymphoma is better than most solid tumors. For $\mathrm{HL}$, it is a potentiate curable tumor with a five-year survival rate $80-90 \%$, whereas in $\mathrm{NHL}$ it reaches $73 \%[2,3]$. Based on the long-term survival for lymphoma patients, accumulating attention were put on the alleviation of the treatment-relative adverse effects.

Glucocorticoids (GC) is frequently applied with chemotherapy to treat lymphoma due to its antilymphoma effect, and to reduce anti-tumor drugs caused vomiting, allergies and other toxicities ${ }^{[4,5]}$. In regard to lymphoma treatment, either prednisone or dexamethasone was a key drug in the frequently used therapy regimens, such as: $\mathrm{CHOP}, \mathrm{EPOCH}, \mathrm{DDGP}, \mathrm{VDLP}{ }^{[6-9]}$. For example, standard six cycles of $\mathrm{CHOP}$ regimen resulted in a cumulative of 3 grams and $24 \mathrm{mg}$ per day for consecutive eighteen weeks, which indicating a long-term medium does GC usage ${ }^{[6,10]}$. It has been reported that long-term GC administration was linked to a risk of GC induced osteoporosis ${ }^{[1-14]}$. Thus, it remains confused for clinicians whether prophylactic anti-osteoporosis treatment is needed and what category drug should be chosen during lymphoma patients administration.

According to recommendation of National Comprehensive Cancer Network (NCCN) guideline for B-cell lymphoma, patients who have received steroid-containing regimens should evaluate $25-\mathrm{OH}$ vitamin $\mathrm{D}$ level, and regularly detect bone mineral density (BMD) when T score between -1.1 and -2.4; furthermore, to supply with vitamin D3 and calcium only when serum level lower than normal, and to use bisphosphonates as first line pharmacologic treatment for osteoporosis ${ }^{[15]}$. However, it was reported that most lymphoma patients were under osteopenia state after initial treatment, undergoing a higher risk of osteoporosis $^{[16]}$. Therefore, whether prophylactic bisphosphonates administration to prevent BMD loss requires to be elucidated.

In this study, we conducted a prospective, randomized controlled phase 3 trial to investigate whether lymphoma patients treated with GC could benefit from bisphosphonates (Zoledronic acid) infusion to decrease the BMD loss and dynamically detected the bone turnover markers.

\section{Patients And Methods}

\section{Study design and participants}

This study is a prospective, randomized controlled phase 3 study done in our cancer center from May, 2016 to July, 2019. Eligible patients were aged 20 years or older and had previously untreated NHL, according to the WHO 2016 classification system, who were bone mineral density (BMD) marker T score at baseline $>-2.5$ at any location. Eligible histology was including $B$ cell NHL and T cell NHL. Patients also had adequate renal function (serum creatinine $<2$ times the upper limit of normal, creatinine clearance $>60 \mathrm{~mL} / \mathrm{min}$ ), normal serum calcium, 25-Hydroxy Vitamin D and parathyroid hormones (PTH). All regimens administered in eligible patients needed to include prednisone 50mg or 100mg d1-d5 q21d or dexamethasone 40mg d1-d4 q21d for at least six cycles. Key exclusion criteria were lymphoma patients with bone or central nervous system involved or had ever used bisphosphonates in the recent six 
months. All patients provided written informed consent. The trial was registered in www.Chictr.org and approved by the ethics committee. (ChiCTR-INR-17010771)

\section{Randomisation and Procedures}

Patients were randomly assigned (1:1) to the Zoledronic acid (ZA) or control group. Randomisation was done with an interactive web response system that assigned a unique patient number, as subject with odd or even number was allocated into ZA group or control group, respectively. All subjects received daily oral calcium (600 mg) and vitamin D3 (0.25 ug) daily at enrollment, continuously for at least one year. ZA group received twice ZA infusion ( $4 \mathrm{mg}$ ) at first treatment cycle and at sixth month. In this process, lymphoma patients appeared with bone involved or neoplastic spinal cord compression or central nervous system involved should be excluded.

\section{Objectives And Assessments}

The primary endpoint was the BMD alternations from enrollment to the twelfth month at the lumbar spine (L1-L4), left hip and left femoral neck, measured by the dual-energy, x-ray absorptiometry scanners, recorded as T score; and new bone fracture during the first year. All patients evaluated the BMD twice: at enrollment and at the end of the twelfth month. Osteoporosis and osteopenia were defined per the definition of the World Health Organization as BMD T score of $<-2.5$ or -1 to -2.5 , separately. The secondary endpoint was the changes of serum bone metabolism biochemical markers, including $\beta-C$ terminal telopeptide of type I collagen ( $\beta$-CTx), bone alkaline phosphatase (BALP) at baseline, 3, 6, 9, 12 months. Additional safety evaluation of ZA in lymphoma patients was also performed in trial.

\section{Statistical analysis}

The age, BMI, serum calcium, 25-hydroxy vitamin D, PTH were recorded as median, as the $T$ score is average $\pm S D$, the statistical methods of comparing the difference between the groups were $\chi 2$ test, Mann-Whitney $u$ test, $t$ test and Wilcoxon rank sum test. All data were analyzed with SPSS 24.0 (IBM Corp., Armonk, NY), and a two-sided $p<0.05$ was considered a statistically significant difference.

\section{Results}

Patients were enrolled between May, 2016 and July, 2019. The data cutoff date for this primary analysis was August, 2020. Of the 84 patients assessed for eligibility, 40 patients randomly assigned to ZA group and only 16 patients completed the study protocol, while 13 patients among the 44 patients in the control group (figure 1). Patients were off the study generally had once ZA infusion, did not regularly take calcium and vitamin D3 orally, were lack of BMD reports or serum BMD turnover biomarkers. Baseline characteristics were generally balanced between the two groups (Table 1). Overall, the median age was 54 years old with a median BMI 23.29 , the ratio of male to female was $1: 1$, and $73 \%$ of female were postmenopausal. There were $82.75 \%$ of patients diagnosed aggressive NHL and majority staged I-II 
(68.97\%). The primary chemotherapy regimens were including CHOP (like), VIPD, DDGP, VDLP, R²-EPOCH and BFM $90^{[17]}$, which all contained high does glucocorticoid. At baseline, the BMD biomarker of serum calcium, 25-hydroxy vitamin D and PTH were all in the normal range. 
Table 1

Baseline characteristics of patients for randomization.

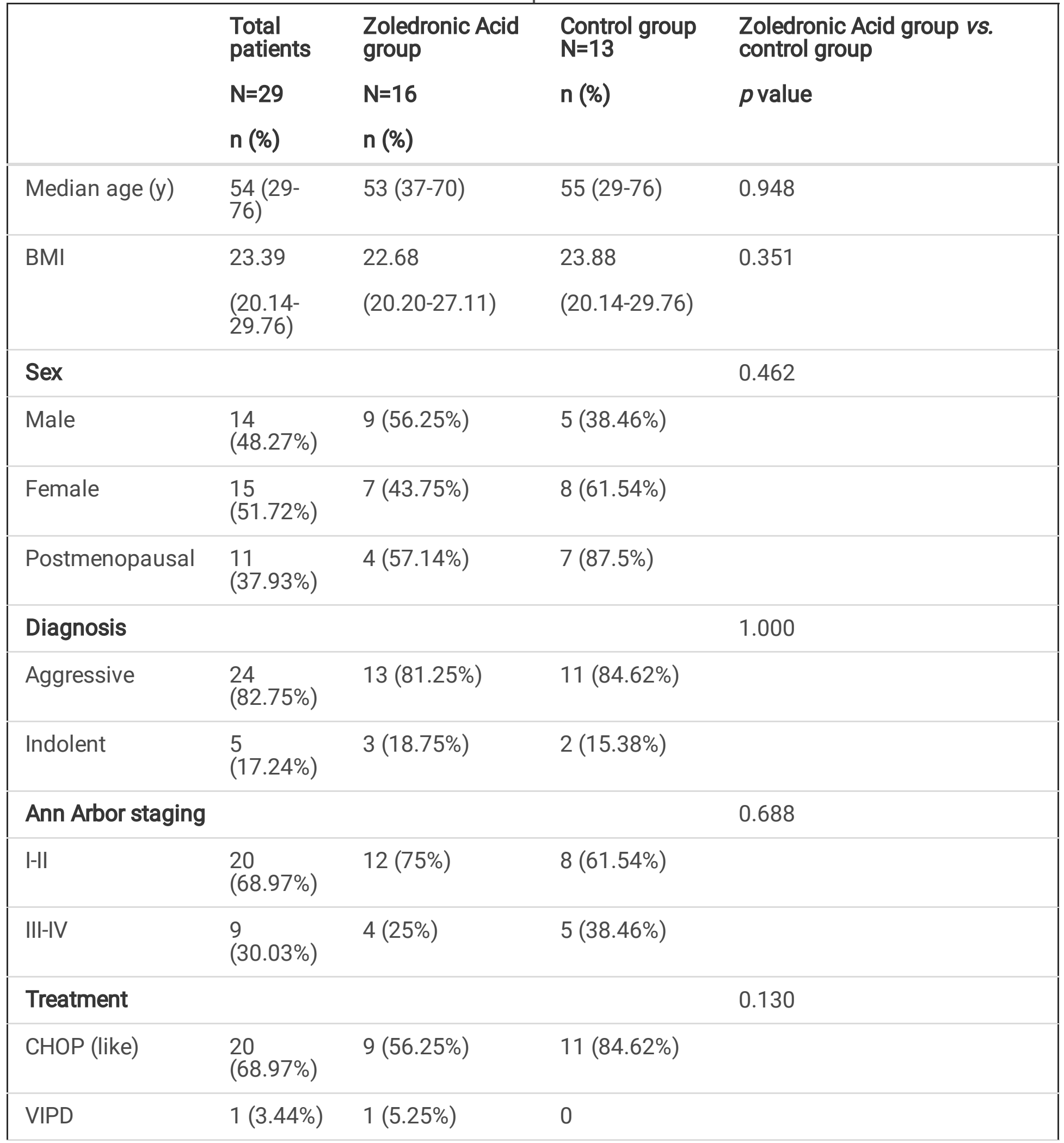

BMI: Body Mass Index; CHOP: cyclophosphamide, doxorubicin, vincristine, and prednisone. VIPD: etoposide, ifosfamide, cisplatin, dexamethasone; DDGP: dexamethasone, cisplatin, gemcitabline, pegaspargase; VDLP; etoposide, dexamethasone, L-asparaginase, cisplatin; $\mathrm{R}^{2}$-EPOCH: rituximab, lenalidomide etoposide, prednisone, vincristine, cyclophosphamide, doxorubicin; BFM-90: see reference 17; PTH: parathyroid hormone, pmol/L. Calcium: mmol/L. 25-hydroxy vitamin D: nmol/L. 


\begin{tabular}{|c|c|c|c|c|}
\hline & $\begin{array}{l}\text { Total } \\
\text { patients }\end{array}$ & $\begin{array}{l}\text { Zoledronic Acid } \\
\text { group }\end{array}$ & $\begin{array}{l}\text { Control group } \\
\mathrm{N}=13\end{array}$ & $\begin{array}{l}\text { Zoledronic Acid group vs. } \\
\text { control group }\end{array}$ \\
\hline & $N=29$ & $N=16$ & n (\%) & $p$ value \\
\hline & n (\%) & n (\%) & & \\
\hline DDGP & $\begin{array}{l}3 \\
(10.34 \%)\end{array}$ & $3(18.75 \%)$ & 0 & \\
\hline VDLP & $\begin{array}{l}3 \\
(10.34 \%)\end{array}$ & $2(12.5 \%)$ & $1(7.69 \%)$ & \\
\hline R2-EPOCH & 1 (3.44\%) & $1(6.25 \%)$ & 0 & \\
\hline BFM-90 & $1(3.44 \%)$ & 0 & $1(7.69 \%)$ & \\
\hline Calcium & 2.27 & 2.28 & 2.27 & 0.714 \\
\hline & $\begin{array}{l}(2.14- \\
4.38)\end{array}$ & $(2.14-2.43)$ & $(2.19-4.38)$ & \\
\hline 25-hydroxy & 37.2 & 39.60 & 36.68 & 0.746 \\
\hline & $\begin{array}{l}(11.77- \\
71.62)\end{array}$ & (11.77-71.68) & $(28.28-50.68)$ & \\
\hline PTH 0 & 4.60 & 4.33 & 4.85 & 0.398 \\
\hline & $\begin{array}{l}(1.36- \\
11.07)\end{array}$ & $(1.36-7.17)$ & $(3.06-11.07)$ & \\
\hline $\begin{array}{l}\text { BMI: Body N } \\
\text { etoposide, if } \\
\text { pegasparga } \\
\text { lenalidomid } \\
\text { reference } 17\end{array}$ & $\begin{array}{l}\text { ex; CHOP: } \\
\text { e, cisplatin } \\
\text {; etoposid } \\
\text { ide, predni } \\
\text { arathyroid }\end{array}$ & $\begin{array}{l}\text { lophosphamide, } \\
\text { examethasone; D } \\
\text { lexamethasone, } L\end{array}$ & $\begin{array}{l}\text { xorubicin, vincr } \\
\text { SP: dexametha } \\
\text { sparaginase, ci } \\
\text { phosphamide, }\end{array}$ & $\begin{array}{l}\text { ine, and prednisone. VIPD: } \\
\text { ne, cisplatin, gemcitabline, } \\
\text { latin; } \mathrm{R}^{2} \text {-EPOCH: rituximab, } \\
\text { xorubicin; BFM-90: see } \\
\text {-hydroxy vitamin D: nmol/L }\end{array}$ \\
\hline
\end{tabular}

With regard the BMD T score, it didn't display statistic significantly difference at any location from baseline data between ZA and control group (Table 2). In total, the average T score of L1-L4 were -0.44, $-0.58,-0.34,-0.19$, respectively; for the left femoral neck, left Ward's triangle, left trochanter major, left hip were $-0.47,-1.08,-0.87,-0.44$, separately. It was $52.38 \%$ that diagnosed osteopenia at baseline $(n=84)$, among them there were $72.73 \%$ of patients older than 50 years old, of which $50 \%$ were women (supplementary table 1). 
Table 2

T score at baseline in randomized patients.

\begin{tabular}{|c|c|c|c|c|}
\hline Location & $\begin{array}{l}\text { Total } \\
\text { patients } \\
\mathrm{N}=29 \\
\text { (mean } \pm S D \text { ) }\end{array}$ & $\begin{array}{l}\text { Zoledronic Acid } \\
\text { group } \\
\mathrm{N}=16 \\
\text { (mean } \pm S D \text { ) }\end{array}$ & $\begin{array}{l}\text { Control } \\
\text { group } \\
\mathrm{N}=13 \\
\text { (mean } \pm S D \text { ) }\end{array}$ & $\begin{array}{l}\text { Zoledronic Acid group vs } \\
\text { control group } \\
p \text { value }\end{array}$ \\
\hline L1 & $-0.44 \pm 1.36$ & $-0.56 \pm 1.54$ & $-0.31 \pm 1.15$ & 0.634 \\
\hline L2 & $-0.58 \pm 1.39$ & $-0.90 \pm 1.15$ & $-0.19 \pm 1.60$ & 0.176 \\
\hline L3 & $-0.34 \pm 1.59$ & $-0.55 \pm 1.30$ & $-0.09 \pm 1.92$ & 0.452 \\
\hline L4 & $-0.19 \pm 1.51$ & $-0.48 \pm 1.19$ & $0.18 \pm 1.81$ & 0.250 \\
\hline $\begin{array}{l}\text { Left femoral } \\
\text { neck }\end{array}$ & $-0.47 \pm 1.08$ & $-0.70 \pm 1.19$ & $-0.18 \pm 0.89$ & 0.206 \\
\hline $\begin{array}{l}\text { Left Ward's } \\
\text { triangle }\end{array}$ & $-1.08 \pm 1.24$ & $-1.37 \pm 1.16$ & $-0.73 \pm 1.28$ & 0.172 \\
\hline $\begin{array}{l}\text { Left trochanter } \\
\text { major }\end{array}$ & $-0.87 \pm 1.17$ & $-1.24 \pm 0.95$ & $-0.41 \pm 1.29$ & 0.056 \\
\hline Left hip & $-0.44 \pm 0.99$ & $-0.68 \pm 0.98$ & $-0.14 \pm 0.96$ & 0.147 \\
\hline
\end{tabular}

The primary endpoint in this trial was the alternation of T score from enrollment to the 12th month at any location. As shown in Table 3, we found a marked improvement of T score in ZA group compared to the control in a year after enrollment at lumbar vertebra (L1-L4). However, in the left femoral neck, Ward's triangle, trochanter major and hip, the data showed no statistic difference between the two groups. Additionally, comparing ZA group with control group, there was no significant difference at the 12 months of the T score (supplementary table 2). Interestingly, we could detect a pronounced deterioration of T score in the control group patients at the 12 months in contrast to that at the enrollment, especially in L1, L2, L4 and left femoral neck, Ward's triangle (supplementary table 3). On the contrary, it presented that a profound increase of T score measured at the 12 months in ZA group after twice infusion of ZA at the L2, L3, L4 locations (supplementary table 4). Moreover, no patient appeared new bone fractures or other bone related symptoms during the treatment and observation periods in both groups. 
Table 3

T score alternations from baseline at 12th month.

\begin{tabular}{|lllll|}
\hline Location & $\begin{array}{l}\text { Total } \\
\text { patients } \\
\mathbf{N}=\mathbf{2 9} \\
(\mathbf{m e a n} \pm \mathrm{SD})\end{array}$ & $\begin{array}{l}\text { Zoledronic Acid } \\
\text { group } \\
\mathbf{N}=\mathbf{1 6} \\
(\mathbf{m e a n} \pm \mathrm{SD})\end{array}$ & $\begin{array}{l}\text { Control group } \\
\mathbf{N}=13 \\
(\mathrm{mean} \pm \mathrm{SD})\end{array}$ & $\begin{array}{l}\text { Zoledronic Acid group vs } \\
\text { control group } \\
\boldsymbol{p} \text { value }\end{array}$ \\
\hline L1 & $-0.07 \pm 0.57$ & $0.14 \pm 0.61$ & $-0.33 \pm 0.40$ & 0.009 \\
\hline L2 & $-0.01 \pm 0.56$ & $0.28 \pm 0.41$ & $-0.35 \pm 0.54$ & 0.003 \\
\hline L3 & $0.02 \pm 0.58$ & $0.23 \pm 0.42$ & $-0.23 \pm 0.66$ & 0.020 \\
\hline L4 & $0 \pm 0.57$ & $0.28 \pm 0.44$ & $-0.35 \pm 0.54$ & 0.020 \\
\hline $\begin{array}{l}\text { Left femoral } \\
\text { neck }\end{array}$ & $-0.16 \pm 0.23$ & $-0.13 \pm 0.22$ & $-0.19 \pm 0.24$ & 0.619 \\
\hline $\begin{array}{l}\text { Left Ward's } \\
\text { triangle }\end{array}$ & $-0.18 \pm 0.32$ & $-0.07 \pm 0.21$ & $-0.32 \pm 0.38$ & 0.092 \\
\hline $\begin{array}{l}\text { Left trochanter } \\
\text { major }\end{array}$ & $0.05 \pm 0.38$ & $0.11 \pm 0.32$ & $-0.02 \pm 0.46$ & 0.170 \\
\hline \begin{tabular}{l} 
Left hip \\
\hline SD: standard deviation.
\end{tabular} & $-0.44 \pm 0.33$ & $-0.02 \pm 0.42$ & $0.08 \pm 0.16$ & 0.144 \\
\hline
\end{tabular}

BMD serum turnover biomarkers could reflect the bone metabolism when glucocorticoid was administered. We dynamically monitored levels of serum $\beta$-CTX and BALP at $0,3,6,9,12$ months in 29 patients. As shown in the Table 4, we observed the $\beta$-CTX and BALP levels at enrollment were $0.76 \pm 1.58$ $\mathrm{ng} / \mathrm{mL}$ and $13.70 \pm 3.84 \mathrm{ug} / \mathrm{L}$ for all patients. In addition, comparing the ZA group to the control group, either $\beta$-CTX or BALP level was similar at baseline. Of note, it started with the 3th month that there appeared significantly reduction of serum $\beta$-CTX and BALP levels in the ZA group in comparison to control group, which continued to the 12th month, $p$ value at all time points $(3,6,9,12$ months) were all < 0.05 . 
Table 4

Serum bone turnover biochemical markers of patients at different times.

\begin{tabular}{|c|c|c|c|c|}
\hline & $\begin{array}{l}\text { Total } \\
\text { patients } \\
\mathrm{N}=29 \\
\text { (mean } \pm \mathrm{SD} \text { ) }\end{array}$ & $\begin{array}{l}\text { Zoledronic Acid } \\
\text { group } \\
\mathrm{N}=16 \\
\text { (mean } \pm \mathrm{SD} \text { ) }\end{array}$ & $\begin{array}{l}\text { Control group } \\
\mathrm{N}=13 \\
\text { (mean } \pm S D \text { ) }\end{array}$ & $\begin{array}{l}\text { Zoledronic Acid group vs. control } \\
\text { group } \\
p \text { value }\end{array}$ \\
\hline \multicolumn{5}{|l|}{$\beta-C T X$} \\
\hline baseline & $0.76 \pm 1.58$ & $0.49 \pm 0.31$ & $0.47 \pm 0.21$ & 0.879 \\
\hline $\begin{array}{l}3 \\
\text { months }\end{array}$ & $0.36 \pm 0.27$ & $0.19 \pm 0.10$ & $0.56 \pm 0.28$ & $<0.001$ \\
\hline $\begin{array}{l}6 \\
\text { months }\end{array}$ & $0.37 \pm 0.29$ & $0.21 \pm 0.12$ & $0.56 \pm 0.32$ & 0.002 \\
\hline $\begin{array}{l}9 \\
\text { months }\end{array}$ & $0.33 \pm 0.24$ & $0.20 \pm 0.14$ & $0.33 \pm 0.24$ & $<0.001$ \\
\hline $\begin{array}{l}12 \\
\text { months }\end{array}$ & $0.31 \pm 0.23$ & $0.20 \pm 0.11$ & $0.45 \pm 0.25$ & 0.004 \\
\hline \multicolumn{5}{|l|}{ BALP } \\
\hline baseline & $13.70 \pm 3.84$ & $13.12 \pm 3.62$ & $14.42 \pm 4.12$ & 0.374 \\
\hline $\begin{array}{l}3 \\
\text { months }\end{array}$ & $11.78 \pm 5.26$ & $8.95 \pm 1.62$ & $15.26 \pm 6.11$ & 0.003 \\
\hline $\begin{array}{l}6 \\
\text { months }\end{array}$ & $12.91 \pm 6.19$ & $9.79 \pm 2.37$ & $16.76 \pm 7.30$ & 0.005 \\
\hline $\begin{array}{l}9 \\
\text { months }\end{array}$ & $13.47 \pm 6.59$ & $10.14 \pm 3.16$ & $17.56 \pm 7.48$ & 0.004 \\
\hline $\begin{array}{l}12 \\
\text { months }\end{array}$ & $13.13 \pm 5.66$ & $10.43 \pm 3.48$ & $16.46 \pm 6.16$ & 0.006 \\
\hline
\end{tabular}

ZA related severe adverse events were not detected during the treatment and follow-up periods. A minority of patients experienced Flu-like symptoms, such as transient fever, rigor, which relieved quickly after nonsteroidal anti-inflammatory drug (NSAIDS) administered. Notably, an extra-nodal NK/T-cell lymphoma, nasal type (ENKTL) patient in ZA group appeared with osteonecrosis of mandible in the follow-up, considering the ZA side effect, we performed tissue biopsy for the lesions that diagnosed as ENKTL involved, excluded the ZA related osteonecrosis.

\section{Discussion}


Our study is a prospective, randomized controlled phase 3 trial conducted in China, to show that prophylactic ZA infusion could benefit GC-treatment lymphoma patients in prevention with osteopenia deterioration; moreover, during the follow-up, no patient experienced osteoporosis or new bone fracture, which reached the primary end point of trial. In this study, ZA usage without an observed severe toxicity, especially the osteonecrosis of mandible. Additionally, sharply decline of serum BMD turnover biomarkers with ZA application may provide an indirect clue for decreased BMD loss.

In Chinese population, a markedly increased BMD loss started between 50 and 69 years of age ${ }^{[18]}$, as the median diagnosis age for lymphoma was around 50 -years to 60 -years old ${ }^{[19]}$, which indicating most lymphoma patients were under BMD loss at diagnosis. From our data, we found that $\mathrm{T}$ score was between -1 and -2.4 at least one location in $52.38 \%$ of the 84 assigned patients at least one location of lumbar spine, femoral and hip at baseline, of which $72.73 \%$ were aged more than 50 years, may suggesting that near three quarters of lymphoma patients at the age $\geq 50$ years were osteopenia before treatment. Consistently, a study from MD. Anderson also presented that around $10 \%$ of lymphoma patients were under osteoporosis and $50 \%$ for osteopenia before initial treatment ${ }^{[20]}$.

Lymphoma patients were at a significant higher risk of an osteoporotic event with a 5-year cumulative rate $10 \%$, in comparison with general population of $6.8 \%$ in Denmark ${ }^{[21]}$. Recently, a study from United Kingdom reported that receipt of R-CHOP in DLBCL patients were at a cumulative risk of $11.4 \%$ for bone fracture at 18 months older than 70 years old ${ }^{[22]}$. In China, an estimated prevalence of osteoporosis to be $6.46 \%$ for men and $29.13 \%$ for women aged $\geq 50$ years $^{[23]}$. Thus, we speculate Chinese lymphoma women older than 50 years with GC-treatment may be at a higher risk of osteoporosis than men. However, in our study, there was no patient with osteoporosis during treatment and follow-up in both groups, which may be explained as small sample size and the short-term follow-up, a longer observation and extended size are needed in the future.

Bisphosphonates is an anti-resorptive drug that widely used to preserve BMD by reducing bone resorption ${ }^{[24]}$. A previous study had been showed pamidronate infusion every 3 months for one year could reduce the trabecular bone loss and the risk of new vertebral fractures in lymphoma patients ${ }^{[25]}$. Zoledronic acid is a third generation of bisphosphonates, showing a higher potent efficacy than pamidronate, and approved for use in osteoporosis or low bone mass ${ }^{[26]}$. It has been reported that ZA usage resulted in a reduction the BMD loss in Americans ${ }^{[27]}$. In agreement, our data presented a result that prophylactic ZA infusion could reduce BMD loss in Chinese populations. Besides, our trial dynamically assessed the serum bone turnover marker $\beta$-CTX and BALP levels. $\beta$-CTX is a referent marker of bone resorption, and BALP regulates bone mineralization, reflecting the bone metabolism ${ }^{[28,29]}$. Contrast to control, ZA group had sharply decreased on both markers since at 3 months till to 12 months, suggesting a rapid inhibition of osteoclastic activity and persistent effect on BMD, which indirectly reflected that ZA could reduce the BMD loss in GC-treatment lymphoma patients. 
On safety, it has been reported that ZA application had a risk of osteonecrosis of mandible ${ }^{[30-32]}$, no case was observed in this cohort as to a short-term observation and the low occurrence rate. Notably, when patients appeared symptoms associated with osteonecrosis of mandible, it is imperative to differentiate the diagnosis of tumor involved or ZA induced adverse effect, as our patient displayed.

Nevertheless, our study had several limitations. First, the patient adherence to medication in this study were poor, leaded to a majority assigned patients exclude from the final data analysis and the cohort was small. Besides, although this study was a prospective, randomized controlled trial, we only included our center patients, not represented the whole Chinese population. Second, our study had set up two groups, both orally taken calcium and vitamin D3, if we had another group as negative control without calcium or vitamin D3 supplements, the T score improvement maybe more significance.

\section{Conclusion}

In this study, we first demonstrated that in China GC-treatment lymphoma patients that prophylactic ZA infusion could relieve BMD loss to prevent osteoporosis without increasing severe adverse effect, providing reference for clinicians to consider ZA application in this situation. Further studies conducted in multicenter are needed to verify these results.

\section{Abbreviations}

HL: Hodgkin lymphoma

NHL: non-Hodgkin lymphoma

ZA: Zoledronic acid

GC: glucocorticoids

BMD: bone mineral density

$\beta$-CTX: $\beta$-C-terminal telopeptide of type I collagen

BALP: bone alkaline phosphatase

BMl: body mass index

PTH: parathyroid hormone

NSAIDS: non-steroidal anti-inflammatory drug

ENKTL: extra-nodal NK/T-cell lymphoma, nasal

\section{Declarations}


Availability of data and materials

The datasets used and/or analyzed during the current study are available from the corresponding author on reasonable request.

\section{Acknowledgements}

The authors thank all those who participated in the recruitment of patients and helped to gather patients' information.

\section{Funding}

Not applicable.

\section{Author information}

Yang $\mathrm{C}$ and Fu $\mathrm{C}$ contributed equally to the work.

Affiliations

Department of Medical Oncology, Cancer Center, West China Hospital, Sichuan University, Chengdu, 610041, China.

Yang $\mathrm{C}$ and Zou L

Department of Pediatrics, West China Second University Hospital, Sichuan University, Chengdu, 610041, China.

Fu C

Department of Medical Oncology, Sun Yat-sen University Cancer Center, Guangzhou, 510060, China.

Weng Huawei

\section{Contributors}

Yang C, Fu C and Weng H: collection of the data. Yang C and Fu C: administrative support and analysis of the data. Zou L: concept and design. All authors: manuscript writing, final approval of the manuscript, and accountability for work.

Corresponding author

Correspondence to Zou L.

Ethics declarations

Ethics approval 
The study protocol was approved by the Ethics Committee of West China Hospital, Sichuan University (Chengdu, China; Approval No. 2017(10)). Informed consent was obtained from each patient. The consent to be obtained from study participants will be written.

\section{Consent for publication}

Not applicable.

\section{Declaration of interests}

The authors declare that they have no competing interests.

\section{References}

1. Shankland KR, Armitage JO, Hancock BW. Non-Hodgkin lymphoma. The Lancet 2012; 380: 848-857.

2. Siegel RL, Miller KD, Fuchs HE, Jemal A. Cancer Statistics, 2021. CA Cancer J Clin 2021;71: 7-33.

3. Shanbhag S, Ambinder RF. Hodgkin lymphoma: A review and update on recent progress. CA: a cancer journal for clinicians 2018; 68: 116-132.

4. Greenstein S, Ghias K, Krett NL, Rosen ST. Mechanisms of glucocorticoid-mediated apoptosis in hematological malignancies. Clinical cancer research: an official journal of the American Association for Cancer Research 2002; 8: 1681-1694.

5. Van Ryckeghem F. Corticosteroids, the oldest agent in the prevention of chemotherapy-induced nausea and vomiting: What about the guidelines? Journal of translational internal medicine 2016; 4: 46-51.

6. Miller TP, Dahlberg S, Cassady JR et al. Chemotherapy alone compared with chemotherapy plus radiotherapy for localized intermediate- and high-grade non-Hodgkin's lymphoma. The New England journal of medicine 1998; 339: 21-26.

7. Purroy N, Bergua J, Gallur L et al. Long-term follow-up of dose-adjusted EPOCH plus rituximab (DAEPOCH-R) in untreated patients with poor prognosis large B-cell lymphoma. A phase II study conducted by the Spanish PETHEMA Group. British journal of haematology 2015; 169: 188-198.

8. Li X, Cui Y, Sun Z et al. DDGP versus SMILE in Newly Diagnosed Advanced Natural Killer/T-Cell Lymphoma: A Randomized Controlled, Multicenter, Open-label Study in China. Clinical cancer research: an official journal of the American Association for Cancer Research 2016; 22: 5223-5228.

9. Jiang $M$, Zhang $H$, Jiang $Y$ et al. Phase 2 trial of "sandwich" L-asparaginase, vincristine, and prednisone chemotherapy with radiotherapy in newly diagnosed, stage IE to IIE, nasal type, extranodal natural killer/T-cell lymphoma. Cancer 2012; 118: 3294-3301.

10. Buttgereit F, da Silva JAP, Boers $M$ et al. Standardised nomenclature for glucocorticoid dosages and glucocorticoid treatment regimens: current questions and tentative answers in rheumatology. Annals of the rheumatic diseases 2002; 61: 718-722. 
11. Buckley L, Humphrey MB. Glucocorticoid-Induced Osteoporosis. The New England journal of medicine 2018; 379: 2547-2556.

12. Chotiyarnwong P, McCloskey EV. Pathogenesis of glucocorticoid-induced osteoporosis and options for treatment. Nature reviews. Endocrinology 2020; 16: 437-447.

13. Weldon D. The effects of corticosteroids on bone growth and bone density. Annals of allergy, asthma \& immunology: official publication of the American College of Allergy, Asthma, \& Immunology 2009; 103.

14. Oray M, Abu Samra K, Ebrahimiadib N et al. Long-term side effects of glucocorticoids. Expert opinion on drug safety $2016 ; 15:$ 457-465.

15. https://.

16. Anargyrou K, Fotiou D, Vassilakopoulos TP et al. Low Bone Mineral Density and High Bone Turnover in Patients With Non-Hodgkin's Lymphoma (NHL) Who Receive Frontline Therapy: Results of a Multicenter Prospective Study. HemaSphere 2019; 3: e303.

17. Schrappe M, Reiter A, Ludwig WD et al. Improved outcome in childhood acute lymphoblastic leukemia despite reduced use of anthracyclines and cranial radiotherapy: results of trial ALL-BFM 90. German-Austrian-Swiss ALL-BFM Study Group. Blood 2000; 95: 3310-3322.

18. Cheng XG, Yang DZ, Zhou Q et al. Age-related bone mineral density, bone loss rate, prevalence of osteoporosis, and reference database of women at multiple centers in China. J Clin Densitom 2007; 10: $276-284$.

19. Swerdlow SH, Campo E, Harris NL et al. WHO Classification of Tumours of Haematopoietic and Lymphoid Tissues. International Agency for Research on Cancer (IARC) 69372 Lyon Cedex 08, France 2017.

20. Thompson MA, Huen A, Toth BB et al. Osteopenia and osteoporosis in untreated non-Hodgkin's lymphoma patients: An important and potentially treatable survivorship issue in lymphoma. Journal of Clinical Oncology 2007; 25: 9055.

21. Baech J, Hansen SM, Jakobsen LH et al. Increased risk of osteoporosis following commonly used first-line treatments for lymphoma: a Danish Nationwide Cohort Study. Leuk Lymphoma 2020; 61: 1345-1354.

22. Booth $\mathrm{S}$, Plaschkes $\mathrm{H}$, Kirkwood AA et al. Fractures are common within 18 months following first-line R-CHOP in older patients with diffuse large B-cell lymphoma. Blood Adv 2020; 4: 4337-4346.

23. Zeng Q, Li N, Wang Q et al. The Prevalence of Osteoporosis in China, a Nationwide, Multicenter DXA Survey. J Bone Miner Res 2019; 34: 1789-1797.

24. Abdou WM, Shaddy AA. The development of bisphosphonates for therapeutic uses, and bisphosphonate structure-activity consideration. ARKIVOC 2009; 143-182.

25. Kim SH, Lim SK, Hahn JS. Effect of pamidronate on new vertebral fractures and bone mineral density in patients with malignant lymphoma receiving chemotherapy. The American journal of medicine 2004; 116: 524-528. 
26. Dhillon S. Zoledronic Acid (Reclast((R)), Aclasta((R))): A Review in Osteoporosis. Drugs 2016; 76: 1683-1697.

27. Westin JR, Thompson MA, Cataldo VD et al. Zoledronic acid for prevention of bone loss in patients receiving primary therapy for lymphomas: a prospective, randomized controlled phase III trial. Clin Lymphoma Myeloma Leuk 2013; 13: 99-105.

28. Szulc P. Bone turnover: Biology and assessment tools. Best Pract Res Clin Endocrinol Metab 2018; 32: $725-738$.

29. Eastell R, Szulc P. Use of bone turnover markers in postmenopausal osteoporosis. The lancet. Diabetes \& endocrinology 2017; 5: 908-923.

30. Yuh D-Y, Chang T-H, Huang R-Y et al. The national-scale cohort study on bisphosphonate-related osteonecrosis of the jaw in Taiwan. Journal of dentistry 2014; 42: 1343-1352.

31. Abrahamsen B. Adverse effects of bisphosphonates. Calcified tissue international 2010; 86: 421435.

32. Gralow JR, Barlow WE, Paterson AHG et al. Phase III Randomized Trial of Bisphosphonates as Adjuvant Therapy in Breast Cancer: S0307. Journal of the National Cancer Institute 2020; 112: 698707.

\section{Figures}

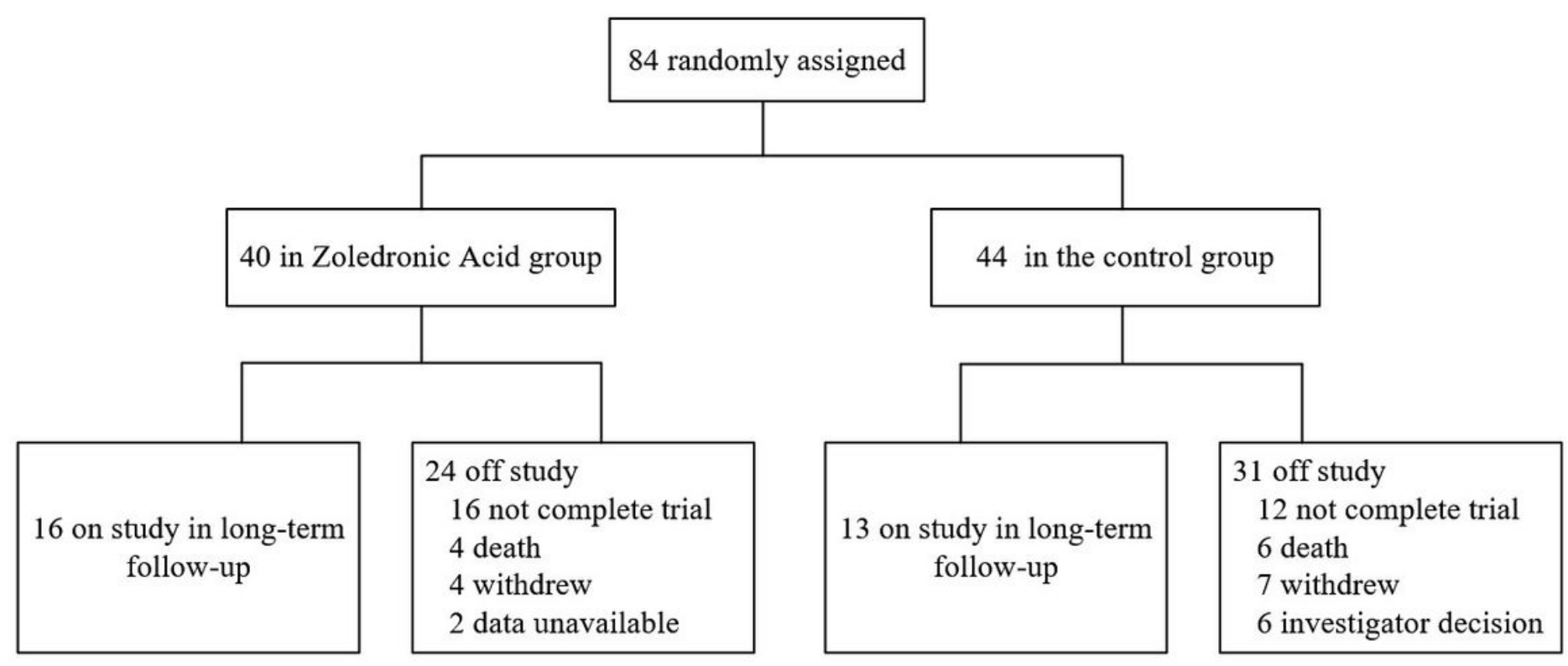

Figure 1

Trial profile.

\section{Supplementary Files}


This is a list of supplementary files associated with this preprint. Click to download.

- supplymentarytables.docx 